\title{
Molecular characteristics and clinical features of pediatric methicillin-susceptible Staphylococcus aureus infection in a medical center in northern Taiwan
}

\author{
Yu-Jen Chen ${ }^{1 \dagger}$, Po-An Chen ${ }^{1 \dagger}$, Chih-Jung Chen ${ }^{1,2}$ and Yhu-Chering Huang ${ }^{1,2^{*}}$
}

\begin{abstract}
Background: There have been no reports regarding clinical features and molecular characteristics of childhood methicillin-susceptible Staphylococcus aureus (MSSA) infections in Taiwan.

Methods: We prospectively collected clinical $S$. aureus isolates from patients aged $<18$ years in a university-affiliated hospital in 2015. Only the first isolate from each patient was included. Medical records were retrospectively reviewed. Patients were classified as community-associated (CA) or healthcare-associated (HA) by the epidemiologic criteria. All MSSA isolates were molecularly characterized.

Results: A total of 495 S. aureus isolates were identified, and 178 (36.0\%) were MSSA. Among the 131 MSSA-infected patients enrolled, 94 (71.8\%) were community-associated and 60 (45.8\%) were inpatients. Patients with HA infections was significantly younger than those with CA infections (median, 15 vs. 67.5 months). The most common specimen of MSSA identified was pus or wound (73.3\%). Compared to HA-MSSA, CA-MSSA isolates were significantly less frequently from sputum ( $6.4 \%$ vs. $27 \%, p=0.001)$. Nineteen pulsotypes were identified. Four pulsotypes accounted for $60 \%$ of the isolates. Isolates of ST15/pulsotype F were more frequently seen in CA than in HA ( $p=0.064)$ while isolates of ST188/pulsotype AX frequently seen in HA ( $p=0.049)$. PVL genes were identified in 11 isolates $(8.4 \%)$, nine of which were characterized as ST59/pulsotype D, same as the local endemic CA-MRSA clone.

Conclusions: MSSA accounted for around one-third of childhood S. aureus infections in northern Taiwan. SSTI was the most common manifestation. The molecular characteristics of these clinical MSSA isolates were relatively diverse and had certain significant differences between CA and HA isolates.
\end{abstract}

Keywords: Methicillin-susceptible Staphylococcus aureus, Children, Taiwan

\section{Background}

Staphylococcus aureus is among the most commonly isolated human pathogens both in the community and in the hospital setting [1].The pathogen can be frequently found in the nose, throat, and on the skin as normal flora [2]. Although S. aureus is not always pathogenic, it can cause a variety of infections in human, including skin-soft tissue infection, respiratory tract infection, pneumonia,

\footnotetext{
* Correspondence: ychuang@cgmh.org.tw

Yu-Jen Chen and Po-An Chen are first two authors equally contributed to the manuscript.

${ }^{1}$ School of Medicine, Chang Gung University, Kweishan, Taoyuan, Taiwan 2Department of Pediatrics, Chang Gung Memorial Hospital at Linkou, No. 5 , Fu-Shin Street, Kweishan, 333 Taoyuan, Taiwan
}

bone/joint infection, endocarditis, sepsis, and toxic shock syndrome [3].

MRSA (methicillin-resistant $S$. aureus) has traditionally been a hospital acquired pathogen and became an increasingly common cause of community-onset infections in the 1990s [4]. However, infections caused by methicillin-susceptible $S$. aureus (MSSA) are still much more frequent than MRSA [5]. Recent studies report that the incidence of MRSA has decreased since the late 2000s [6], while MSSA infections have increased or at least remained stable [7, 8]. In Taiwan, incidence of MSSA infection was reported to be 0.132 episode per 100 discharges in 2007 [9] and our previous report

(c) The Author(s). 2019 Open Access This article is distributed under the terms of the Creative Commons Attribution 4.0 International License (http://creativecommons.org/licenses/by/4.0/), which permits unrestricted use, distribution, and 
showed that MSSA accounted for one-third of childhood S. aureus infection between 2006 and 2012 in a medical center situated in northern part of Taiwan [10]. Some studies from Europe found that the overall annual incidence rate of MSSA bacteremia was 10-fold higher than that of MRSA bacteremia from 2000 to 2008 [8]. Therefore, the epidemiology of MSSA is as important as MRSA nowadays.

In Taiwan, MRSA has prevailed more common than MSSA clinically and has attracted more attention and studies $[9,10]$. Studies regarding the clinical features as well as molecular characteristics of MSSA infections have been scanty [11, 12], all focusing on adult patients, and none from pediatric patients. Therefore, we conducted this study to figure out the clinical features and molecular characteristics of pediatric MSSA infections in Taiwan.

\section{Methods}

\section{Population}

This study was conducted in Chang Gung Memorial Hospital (CGMH) at Linkou, which is a university-affiliated teaching hospital in northern Taiwan and provides a range of care, from primary to tertiary care, with 3700 beds. From January 1, 2015 to December 31 , 2015, all the clinical S. aureus isolates from children less than 18 years of age, excluding the isolates from neonatal units and survey for colonization, were prospectively collected and stored by the microbiology laboratory of CGMH. For MSSA isolates, we retrospectively reviewed the medical records of the patients. If there were multiple episodes (isolates) collected from a single patient, only the first episode (isolate) was included for analysis. We classified MSSA-infected patients as healthcare-associated (HA) and community-associated (CA) using the Centers for Disease Control and Prevention definition for MRSA [3, 13, 14]. "HA" infection was defined as the patient with MSSA infection identified $48 \mathrm{~h}$ after hospitalization or having prior healthcare exposure history within 1 year prior to the episode, including residence in a long-term care facility, prior admission to an acute care facility, prior surgical procedures, the use of central intravenous catheters or long-term venous access devices, the use of urinary catheters, the use of other long-term percutaneous devices, and/ or the requirement of dialysis. "CA" infection was defined as the patient having MSSA infection identified within $48 \mathrm{~h}$ of hospitalization and without aforementioned history within 1 year before the episode. HA infection was further categorized into hospital-onset $(\mathrm{HO})$ and community-onset $(\mathrm{CO})$ based on the timing of specimens collected. The samples collected at outpatient department or within $48 \mathrm{~h}$ of hospitalization were categorized as $\mathrm{CO}$ [15] and those collected after $48 \mathrm{~h}$ of hospitalization were categorized as $\mathrm{HO}[10,16]$.
The study was approved by the Institutional Review Board (IRB) of CGMH and informed consents from the patients/guardians were waived.

\section{Definition of the diagnosis}

Primary bacteremia was defined as blood cultures positive for MSSA without apparent infectious foci. The diagnosis of pneumonia composed of clinical symptoms (fever with respiratory symptoms) and a radiographic confirmation [17]. Urinary tract infection (UTI) was defined as a significant bacteriuria $(\geq 100,000$ colony forming units from a cleanly voided sample or $>50,000$ colony forming units from catheter sample [18]) with pyuria [19]. Those with colonies of MSSA isolates not reaching the amount as significant bacteriuria $(\leq 100,000$ colony forming units from a cleanly voided sample or $<50,000$ colony forming units from catheter sample) were excluded for further analysis.

\section{Antibiotic susceptibility testing}

The antimicrobial susceptibility of all MSSA isolates to 10 antibiotics, including penicillin, trimethoprim/sulfamethoxazole (SXT), ciprofloxacin, clindamycin, erythromycin, doxycycline, fusidic acid, teicoplanin and linezolid, was determined by the disk-diffusion method, while vancomycin was determined by minimal inhibition concentration, following the 2016 Guideline of Clinical and Laboratory Standard Institutes [20].

\section{Molecular characterizations}

Molecular methods used included pulsed-field gel electrophoresis (PFGE) by SmaI digestion and detection of the Panton-Valentine leukocidin (PVL) genes as previously described [10]. Some isolates of representative PFGE patterns were selected for further characterization by multilocus sequence typing (MLST), and spa typing. Sequence type (ST) was given according to sequence allelic profiles using the MLST database (https://pubmlst. org/saureus/) [21]. The spa genes were sequenced and spa types were assigned corresponding to the spa database (http://spa.ridom.de/spatypes.shtml).

\section{Statistics}

The associations between the clinical presentations of MSSA-infected patients among the two groups were compared using the Kruskal-Wallis one-way analysis of variance (ANOVA) or Fisher's exact test. A $p$ value of less than 0.05 was considered significant. All analyses were performed by SPSS 17.0 for Windows.

\section{Results}

Patient characteristics and infection foci

During the study period, a total of $495 \mathrm{~S}$. aureus isolates were included, and 178 (36.0\%) from 160 patients were 
MSSA.14 patients had multiple isolates, including 11 patients with 2 isolates, two patients with three isolates and one patient with four isolates. Among the 160 patients enrolled, 29 patients with bacteriuria were excluded and a total of 131 patients were finally included for analysis. Of the 131 patients, 94 (71.8\%) were classified as CA and $37(28.2 \%)$ as HA. The distribution of these patients is shown in Table 1. Seventy-one patients (54.2\%) were treated as outpatients or visitors of emergency department (OPD/ED), whereas $60(45.8 \%)$ were from inpatients. Among the 71 OPD/ED, 65 (91.5\%) were CA and only 6 as HA. Patients with HA infection were younger than those with CA (median age, 15 months (4-156) vs. 67.5 months (22.3-165)). The patients with HA infection were significantly more likely to have underlying diseases, and among the listed underlying diseases, more likely to be preterm patients and have neurological problems such as cerebral palsy and epilepsy (all $P<0.05$ ).
The detailed distribution of the specimens of these MSSA isolates identified is shown in Table 2. Pus or wound accounted for the largest proportion of both CA and HA patients (79.8 and 56.8\%, respectively). Compared to HA-MSSA, CA-MSSA isolates were significantly less frequently identified from sputum $(6.4 \%$ vs. $27.0 \%, p=0.001)$ while significantly more frequently identified from pus or wound $(P=0.007)$.

\section{Clinical presentations of MSSA infections}

Clinical manifestations of these MSSA infections included SSTIs $(n=95)$, pneumonia $(n=16)$, primary bacteremia $(n=8)$, otitis media $(n=7)$, central catheter infection $(n=2)$, osteomyelitis $(n=1)$, septic arthritis $(n=1)$, and UTI $(n=1)$. More than $90 \%$ of the cases recovered uneventfully. One developed septic shock. Four patients eventually died during hospitalization but were not attributed to MSSA infections.

Table 1 Comparison of demographics and clinical outcomes of pediatric patients with MSSA Infection stratified by the origin of infections

\begin{tabular}{|c|c|c|c|c|c|}
\hline \multirow[t]{2}{*}{ Characteristics } & \multirow{2}{*}{$\begin{array}{l}\text { CA }(n=94) \\
\text { No. }(\%)\end{array}$} & \multirow{2}{*}{$\begin{array}{l}\text { HA ( } n= \\
37) \\
\text { No. (\%) }\end{array}$} & \multirow{2}{*}{$\begin{array}{l}P \\
\text { value }\end{array}$} & \multicolumn{2}{|l|}{$\mathrm{HA}$} \\
\hline & & & & $\begin{array}{l}\mathrm{CO}(n=17) \\
\text { No. }(\%)\end{array}$ & $\begin{array}{l}\mathrm{HO}(n=20) \\
\text { No. }(\%)\end{array}$ \\
\hline \multicolumn{6}{|l|}{ Demographics } \\
\hline Age in month median, IQR) & $67.5(22.3-165)$ & $15(4-156)$ & & $66(5.5-168.5)$ & $6(3-75)$ \\
\hline Male sex (male\%) & $63(67)$ & $21(56.8)$ & 0.270 & $10(58.8)$ & $11(55)$ \\
\hline \multicolumn{6}{|l|}{ Underlying Diseases } \\
\hline None (\%) & $61(46.6)$ & $15(40.5)$ & 0.011 & $6(35.3)$ & $9(45)$ \\
\hline Atopic syndrome (\%) & $14(10.7)$ & $1(2.7)$ & 0.049 & $0(0)$ & $1(5)$ \\
\hline Preterm (\%) & $0(0)$ & $7(18.9)$ & 0 & $0(0)$ & $7(35)$ \\
\hline Immunodeficiency (\%) & $0(0)$ & $1(2.7)$ & 0.110 & $1(5.9)$ & $0(0)$ \\
\hline Renal Diseases (\%) & $1(1)$ & $1(2.7)$ & 0.491 & $1(5.9)$ & $0(0)$ \\
\hline Urogenital problems (\%) & $0(0)$ & $2(5.4)$ & 0.023 & $1(5.9)$ & $1(5)$ \\
\hline Gastrointestinal problems (\%) & $0(0)$ & $1(2.7)$ & 0.110 & $0(0)$ & $1(5)$ \\
\hline Cardiovascular diseases (\%) & $1(1)$ & $1(2.7)$ & 0.491 & $1(5.9)$ & $0(0)$ \\
\hline Malignancies and Hematologic Diseases (\%) & $0(0)$ & $2(5.4)$ & 0.023 & $1(5.9)$ & $1(5)$ \\
\hline Metabolic Diseases (\%) & $2(1.5)$ & $1(2.7)$ & 0.843 & $0(0)$ & $1(5)$ \\
\hline Neurological Diseases (\%) & $5(3.8)$ & $7(18.9)$ & 0.015 & $7(41.2)$ & $0(0)$ \\
\hline ENT anomaly (\%) & $12(9.2)$ & $3(8.1)$ & 0.451 & $3(17.6)$ & $0(0)$ \\
\hline Inpatient (\%) & $29(22.1)$ & $31(83.8)$ & 0 & $11(64.7)$ & $20(100)$ \\
\hline \multicolumn{6}{|l|}{ Outcome } \\
\hline Septic shock (\%) & $1(0.8)$ & $0(0)$ & & & \\
\hline Attributable mortality (\%) & $0(0)$ & $0(0)$ & & & \\
\hline Non-attributable mortality (\%) & $0(0)$ & $3(8.1)$ & & & \\
\hline Recurrent infection (\%) & $3(2.3)$ & $0(0)$ & & & \\
\hline Uneventfully (\%) & $88(93.6)$ & $34(91.9)$ & & & \\
\hline
\end{tabular}

CA community-associated, HA healthcare-associated, $\mathrm{CO}$ community onset, $\mathrm{HO}$ hospital onset 
Table 2 Distribution of the specimens of 131 MSSA isolates identified from pediatric patients

\begin{tabular}{|c|c|c|c|c|c|c|c|}
\hline \multirow[t]{2}{*}{ Types of specimens } & \multirow{2}{*}{$\begin{array}{l}\text { Inpatients } \\
(n=60) \\
\text { No. }(\%)\end{array}$} & \multirow{2}{*}{$\begin{array}{l}\text { Outpatients } \\
(n=71) \\
\text { No. }(\%)\end{array}$} & \multirow{2}{*}{$\begin{array}{l}\text { CA }(n= \\
94) \\
\text { No. }(\%)\end{array}$} & \multirow{2}{*}{$\begin{array}{l}\text { HA }(n= \\
37) \\
\text { No. (\%) }\end{array}$} & \multirow[t]{2}{*}{$P$} & \multicolumn{2}{|l|}{$\mathrm{HA}$} \\
\hline & & & & & & $\begin{array}{l}\mathrm{CO}(n=17) \\
\text { No. }(\%)\end{array}$ & $\begin{array}{l}\mathrm{HO}(n=20) \\
\text { No. }(\%)\end{array}$ \\
\hline Bloodstream (\%) & $2(3.3)$ & $6(8.5)$ & $6(6.4)$ & $2(5.4)$ & 0.833 & $0(0)$ & $2(10)$ \\
\hline Central venous catheter (\%) & $2(3.3)$ & $0(0)$ & $0(0)$ & $2(5.4)$ & 0.023 & $2(11.8)$ & $0(0)$ \\
\hline Sputum (\%) & $15(25)$ & $1(1.4)$ & $6(6.4)$ & $10(27)$ & 0.001 & $5(29.4)$ & $5(25)$ \\
\hline Pus or wound (\%) & $35(58.3)$ & $61(85.9)$ & $75(79.8)$ & $21(56.8)$ & 0.007 & $9(52.9)$ & $12(60)$ \\
\hline Urine (\%) & $1(1.7)$ & $0(0)$ & $0(0)$ & $1(2.7)$ & 0.110 & $0(0)$ & $1(5)$ \\
\hline Ear discharge (\%) & $4(6.7)$ & $3(4.2)$ & $6(6.4)$ & $1(2.7)$ & 0.399 & $1(5.9)$ & $0(0)$ \\
\hline Synovial fluid (\%) & $1(1.7)$ & $0(0)$ & $1(1)$ & $0(0)$ & 0.529 & $0(0)$ & $0(0)$ \\
\hline
\end{tabular}

$C A$ community-associated, $H A$ healthcare-associated, $\mathrm{CO}$ community onset, $\mathrm{HO}$ hospital onset

Skin and soft tissue infections were the most common presentation for both CA and HA MSSA infections. Thirty-five out of 95 were hospitalized (36.8\%). The outcomes were generally uneventful. Two patients had two isolates within 14 days. The first case was an 8 -year-old boy without underlying disease who suffered from otitis externa initially. Recurrent infection of otitis externa was noted after one course of antibiotics treatment and MSSA was identified from the pus again. The other case was a 2-year-old girl without underlying disease. She was diagnosed as pre-auricular fistula in the first visit. After antibiotics treatment for 2 weeks, pre-auricular abscess was still noted and the second pus specimen still yielded MSSA.

Pneumonia occurred in 16 children. Fifteen of them were inpatients and five of them were CA (33.3\%). The average hospital stay of these patients was 87.3 days (61.6 days for CA cases and 100.4 days for HA cases), which was the longest of all the infections. One of them experienced a complicated clinical course and MSSA non-attributable death occurred in three patients. A 12-month-old male had MSSA pneumonia, received a 10-day course of antibiotic treatment and was discharged. Lung abscess and septic shock was noted 3 days after discharge and re-admitted for a complete course of intravenous antibiotics therapy. Two preterm infants suffering from respiratory distress syndrome and severe bronchopulmonary dysplasia had MSSA isolates identified from sputum during hospitalization. One died later due to pneumonia caused by Acinetobacter nosocomialis and the other due to severe bronchopulmonary dysplasia. The third case, a 4-month-old male infant without systemic disease, encountered a life-threatening event, was intubated, MSSA identified from the sputum during hospitalization and eventually died.

Primary bacteremia occurred in 8 children and only two of them was inpatient. Both inpatients were grouped in HA (HO)-MSSA. Central catheter-related infection was identified in two inpatients. All of them recovered uneventfully.
Osteomyelitis occurred in a 17-year-old adolescent, who suffered from an open fracture after a traffic accident, MSSA identified from chronic wound and recovered uneventfully after antibiotic treatment. Septic arthritis occurred in one inpatient with uneventful outcome after a course of antibiotic regimen.

\section{Molecular typing}

Detailed molecular characteristics of the 131 isolates including PFGE, MLST (performed for selected isolates) and spa typing (performed for selected isolates) are shown in Table 3. A dendrogram for all 19 pulsotypes with the cut-off value is provided in Fig. 1. Except three untypeable isolates, nineteen pulsotypes were identified. Four pulsotypes, including types BA (18.3\%), AX (16.8\%), F (14.5\%) and BW (10.7\%), accounted for $60.3 \%$ of the 131 isolates. Pulsotype AX accounted for a borderline significantly higher proportion of HA isolates $(27 \%)$ than CA isolates $(12.8 \%)(p=0.049)$ while pulsotype $\mathrm{F}$ accounted for a higher proportion of $\mathrm{CA}$ isolates (18.1\%) than HA isolates (5.4\%) but did not reach a significant difference $(p=0.064)$. MLST typing was performed in 44 selected samples among each PFGE type and except for five untypeable isolates a total of 20 sequence types were identified, with singletons for 9 isolates. For pulsotype AX, all five isolates selected showed ST188 (5/5). For pulsotype BA and F, ST7 (4/6) and ST15 (6/6) are dominant MLST types, respectively. As for spa typing, 56 isolates were analyzed and except for five untypeable isolates 32 spa types were identified with at least three newly identified types. Nine of 22 PFGE type AX isolates were analyzed, and all of them presented spa t189. Generally, isolates of ST15/pulsotype $F$ were more frequently seen in CA than in HA with borderline significance $(P=0.064)$ while isolates of ST188/pulsotype AX were significantly frequently seen in HA $(p=0.049)$.

The isolates unable to be successfully typed by MLST were clustered in two pusotypes, namely type BW and BI. All 14 isolates with pulsotype BW were re-examined 
Table 3 Molecular characteristics of 131 methicillin-sensitive Staphylococcus aureus isolates from pediatric patients stratified by pulsotypes

\begin{tabular}{|c|c|c|c|c|c|c|c|c|}
\hline Characteristics & BA & $A X$ & $\mathrm{~F}$ & BW & AK & $\mathrm{D}$ & $S$ & Others \\
\hline $\begin{array}{l}\text { No. isolates } \\
(n=131)\end{array}$ & $24(18.3 \%)$ & $\begin{array}{l}22 \\
(16.8 \%)\end{array}$ & $19(14.5 \%)$ & $14(10.7 \%)$ & $10(7.6 \%)$ & $9(6.9 \%)$ & $7(5.3 \%)$ & $26(19.8 \%)$ \\
\hline CA $(n=94)$ & 18 (19.1\%) & $\begin{array}{l}12 \\
(12.8 \%)\end{array}$ & $17(18.1 \%)$ & $10(10.6 \%)$ & $9(9.8 \%)$ & $5(5.3 \%)$ & $6(6.4 \%)$ & 17 (18.1\%) \\
\hline $\mathrm{HA}(n=37)$ & $6(16.2 \%)$ & $\begin{array}{l}10 \\
(27.4 \%)\end{array}$ & $2(5.4 \%)$ & $4(10.8 \%)$ & $1(2.7 \%)$ & $\begin{array}{l}4 \\
(10.8 \%)\end{array}$ & $1(2.7 \%)$ & $9(24.3 \%)$ \\
\hline$p$-value & 0.696 & 0.049 & 0.064 & 0.977 & 0.182 & 0.263 & 0.399 & 0.420 \\
\hline $\begin{array}{l}\text { PVL-positive } \\
(n=11)\end{array}$ & 0 & 0 & 0 & 0 & 0 & 9 & 0 & 2 \\
\hline $\begin{array}{l}\text { Sequence } \\
\text { type }\end{array}$ & $7(4 / 6), 8(1 / 6), 6(1 / 6)$ & $188(5 / 5)$ & $15(6 / 6)$ & $\begin{array}{l}\text { nontypeable } \\
(3 / 3)\end{array}$ & $\begin{array}{l}508(3 / 5) \\
3563(1 / 5) \\
3375(1 / 5)\end{array}$ & $59(2 / 2)$ & $5(2 / 2)$ & $\begin{array}{l}1281 \text { (2), nontypeable (2), } \\
1,8,12,30,59,182,398, \\
573,623,834,1301\end{array}$ \\
\hline spa type & $\begin{array}{l}\text { t091(2/9), t008(1/9), } \\
\text { t701(1/9), t1943(1/9), } \\
\text { t3071(1/9), t3864(1/9), } \\
\text { t3992(1/9), t16261(1/9) }\end{array}$ & $\begin{array}{l}\mathrm{t} 189 \\
(9 / 9)\end{array}$ & $\begin{array}{l}\text { t084 (4/9), } \\
\text { t7200(2/9), } \\
\text { t346(1/9), } \\
\text { t3024(1/9), } \\
\text { t16565(1/9) }\end{array}$ & $\begin{array}{l}\text { nontypeable } \\
(2 / 2)\end{array}$ & $\begin{array}{l}\text { t015 }(2 / 6), \\
\text { t116 }(2 / 6), \\
\text { t073 }(1 / 6) \\
\text { t16564 }(1 / 6)\end{array}$ & $\begin{array}{l}\mathrm{t} 437 \\
(2 / 3) \\
\mathrm{t} 1950 \\
(1 / 3)\end{array}$ & $\begin{array}{l}\text { t002 }(2 / 3) \\
\text { nontypeable } \\
(1 / 3)\end{array}$ & $\begin{array}{l}\text { nontypeable (2), t008, t012, } \\
\text { t164, t213, t364, t437, } \\
\text { t1250, t1379, t2182, t3406, } \\
\text { t8940, t16297, t16298 }\end{array}$ \\
\hline
\end{tabular}

PVL Panton-Valentine leucocidin genes

by biochemistry tests and MALDI-TOF (matrix-assisted laser desorption/ionization time0of-flight mass spectrometer) and were confirmed as $S$. aureus. Three isolates were selected for MLST and 4 of 7 segments (arc, gmk, pta, tpi) could be amplified and sequenced successfully, all revealing the same sequences. However, the other three segments could not be either amplified or sequenced successfully and thus was categorized as untypeable.
PVL genes were identified in 11 isolates (8.4\%), and nine of them were characterized as ST59/pulsotype D, same as the local endemic CA-MRSA clone in Taiwan. Nine of them were associated with SSTI and seven patients were male (Table 4).

\section{Antibiotics sensitivity test}

The results of antibiotic susceptibility test are shown in Table 5. All 131 isolates were sensitivity to Linezolid,

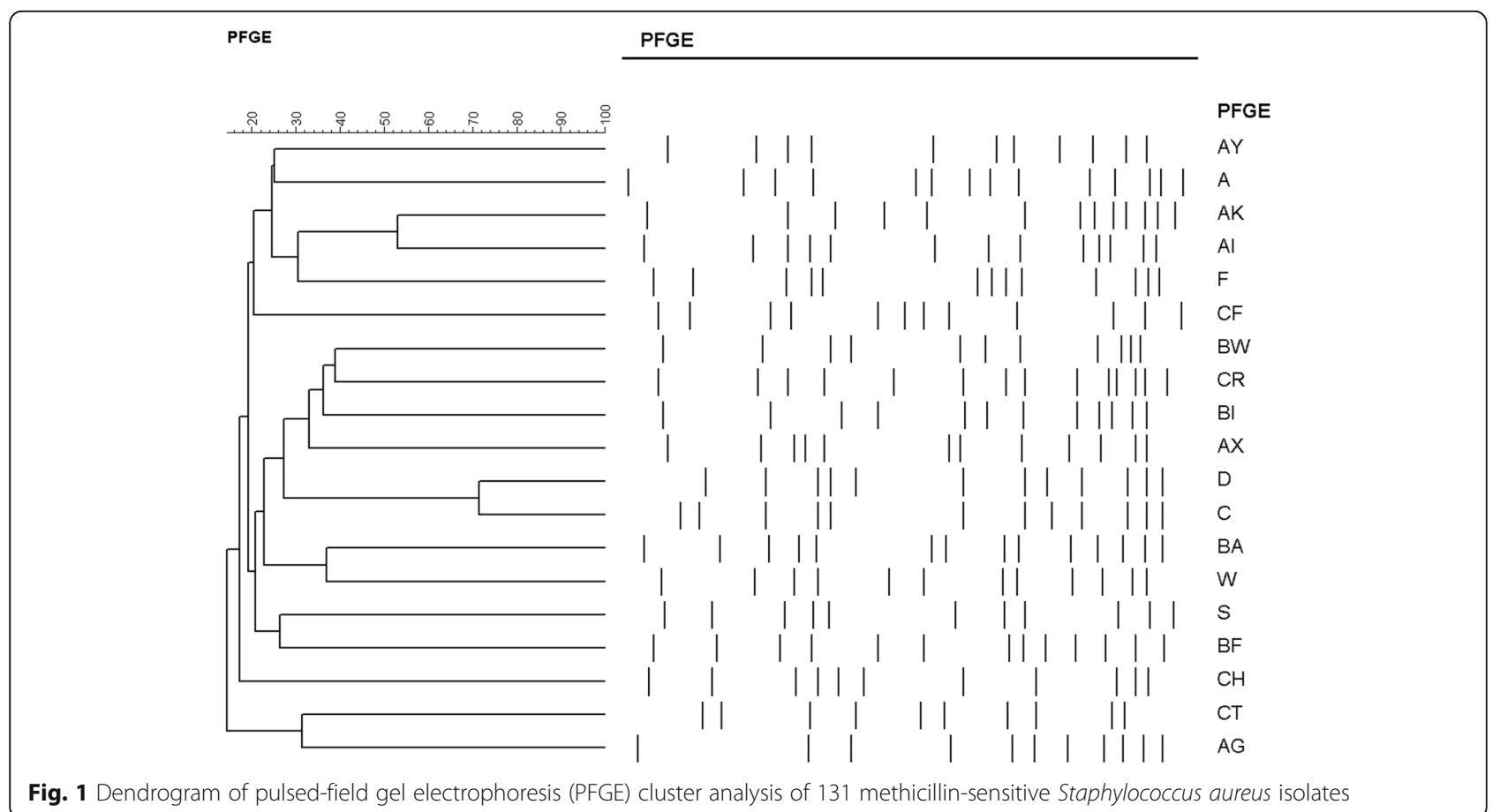


Table 4 Clinical and molecular features of the 11 patients with Panton-Valentine leucocidin-positive MSSA isolates

\begin{tabular}{|c|c|c|c|c|c|c|c|c|}
\hline $\begin{array}{l}\text { Age range } \\
\text { (years) }\end{array}$ & Gender & $\begin{array}{l}\mathrm{IP} / \\
\mathrm{OP}\end{array}$ & Underlying diseases & Diagnosis & $\begin{array}{l}\text { Onset } \\
\text { Group }\end{array}$ & Outcome & PFGE & MLST-spa \\
\hline $5-10$ & F & $\mathrm{OP}$ & None & $\begin{array}{l}\text { Primary } \\
\text { bacteremia }\end{array}$ & CA & Uneventfully & $C T$ & $\begin{array}{l}\text { ST1301- } \\
\text { t8940 }\end{array}$ \\
\hline$<1$ & M & IP & None & SSTI & CA & Uneventfully & $\mathrm{Al}$ & ST8-t008 \\
\hline $5-10$ & M & $\mathrm{OP}$ & None & SSTI & CA & Uneventfully & $D$ & .. \\
\hline$>10$ & F & $\mathbb{I P}$ & None & SSTI & CA & Uneventfully & $\mathrm{D}$ & ST59-t1950 \\
\hline $5-10$ & M & $\mathrm{OP}$ & None & SSTI & CA & Uneventfully & D & .. \\
\hline $1-4$ & M & IP & None & SSTI & CA & Uneventfully & $D$ & .. \\
\hline$>10$ & M & $\mathrm{OP}$ & Atopic & SSTI & CA & Uneventfully & D & ST59-t437 \\
\hline$>10$ & M & $\mathrm{OP}$ & None & SSTI & $\mathrm{HACO}$ & Uneventfully & $\mathrm{D}$ &. \\
\hline$<1$ & M & $\mathbb{P}$ & $\begin{array}{l}\text { Preterm, Cardiovascular } \\
\text { disease }\end{array}$ & Pneumonia & $\mathrm{HO}$ & $\begin{array}{l}\text { Non-attributable } \\
\text { mortality }\end{array}$ & D &. \\
\hline $5-10$ & F & IP & None & SSTI & $\mathrm{HO}$ & Uneventfully & D & \\
\hline$<1$ & $\mathrm{~F}$ & $\mathbb{P}$ & None & SSTI & $\mathrm{HO}$ & Uneventfully & D & .. \\
\hline
\end{tabular}

IP inpatient, OP outpatient, PFGE pulsed-field gel electrophoresis, MLST multi-locus sequence typing, CA community-associated, HA healthcare-associated, CO community onset, $\mathrm{HO}$ hospital onset

teicoplanin, and vancomycin, and more than $95 \%$ of the isolates were susceptible to TMP-SMX, Fusidic acid, ciprofloxacin and doxycycline. The overall sensitivity rate to clindamycin and erythromycin were 79.4 and $69.5 \%$ respectively. The susceptibility rate of HA isolates $(22 \%)$ to penicillin was significantly higher than that of CA isolates $(2.2 \%) \quad(p<0.01)$ while CA isolates had significantly higher susceptible rate to TMP-SMX $(100 \%)$ than did HA isolates $(95 \%)(p=0.006)$.

\section{Discussion}

To our knowledge, this is the first study regarding the clinical features and molecular characteristics of pediatric MSSA infections in Taiwan. In this study, the most common clinical manifestation was SSTI, which accounted for nearly three quarters of the MSSA infections. The patients with HA-MSSA infections were significantly younger than those with CA-MSSA infections and were significantly associated with the underlying diseases of preterm and neurologic diseases. Significantly more patients with HA-MSSA infections manifested as pneumonia than those with CA-MSSA infections, while more patients with CA-MSSA manifested as SSTI. That nearly $70 \%$ of the patients manifesting pneumonia had underlying diseases may be able to explain this finding.

Clinical manifestations of childhood MSSA infection in this study were similar to those for childhood MRSA infection in Taiwan [10]. Whereas, compared to MRSA in Taiwan, which has its dominant clones in each CA- or HA- classification (major clone for CA-MRSA

Table 5 Distribution of antimicrobial susceptibility test results of 131 methicillin-sensitive Staphylococcus aureus isolates from pediatric patients stratified by origin of acquisition

\begin{tabular}{|c|c|c|c|c|c|c|}
\hline \multirow[t]{2}{*}{ Antibiotics } & \multirow{2}{*}{$\begin{array}{l}\text { CA } \\
(n=94) \\
\text { No. }(\%)\end{array}$} & \multirow{2}{*}{$\begin{array}{l}\text { HA }(n=37) \\
\text { No. }(\%)\end{array}$} & \multirow[t]{2}{*}{$P$} & \multicolumn{2}{|l|}{$\mathrm{HA}$} & \multirow[b]{2}{*}{ P } \\
\hline & & & & $\begin{array}{l}\mathrm{CO}(n=17) \\
\text { No. }(\%)\end{array}$ & $\begin{array}{l}\mathrm{HO}(n=20) \\
\text { No. }(\%)\end{array}$ & \\
\hline Clindamycin (\%) & $75(80)$ & $29(78)$ & 0.858 & $12(71)$ & $17(85)$ & 0.289 \\
\hline Erythromycin (\%) & $66(70)$ & $25(68)$ & 0.767 & $11(65)$ & $14(70)$ & 0.732 \\
\hline Fusidic acid (\%) & $93(99)$ & $35(95)$ & 0.135 & $17(100)$ & $18(90)$ & 0.180 \\
\hline Linezolid (\%) & $94(100)$ & $36 / 36^{a}(100)$ & - & $17(100)$ & $19 / 19^{\mathrm{a}}(100)$ & - \\
\hline Penicillin (\%) & $2(2)$ & $8 / 36^{a}(22)$ & 0 & $4(24)$ & $4 / 19^{a}(21)$ & 0.858 \\
\hline Sufamethoxazole-Trimethoprim (\%) & $94(100)$ & $34 / 36^{\mathrm{a}}(94)$ & 0.021 & $16(94)$ & $18 / 19^{\mathrm{a}}(95)$ & 0.935 \\
\hline Teicoplanin (\%) & $94(100)$ & $36 / 36^{\mathrm{a}}(100)$ & - & $17(100)$ & $19 / 19^{\mathrm{a}}(100)$ & - \\
\hline Vancomycin (\%) & $94(100)$ & $36 / 36^{\mathrm{a}}(100)$ & - & $17(100)$ & $19 / 19^{\mathrm{a}}(100)$ & - \\
\hline iprofloxacin (\%) & $93(99)$ & $37(100)$ & 0.529 & $17(100)$ & $20(100)$ & - \\
\hline Doxycycline (\%) & $92(98)$ & $35(95)$ & 0.326 & $15(88)$ & $20(100)$ & 0.115 \\
\hline
\end{tabular}


is ST59 while ST239 and ST5 for HA-MRSA) [22, 23], the molecular characteristics of MSSA isolates from pediatric patients in this study were relatively diverse and only one clone had significant difference between $\mathrm{CA}$ and $\mathrm{HA}$ isolates. Three clones, namely ST188/pulsotype AX, ST15/pulsotype F, ST7 or 8/pulsotype BA, accounted for half of the isolates. These findings were consistent with those in adult patients reported from Taiwan [12, 24, 25], which showed that ST188 was the most common sequence type. The clones of ST7, and ST188 (or spa t189) also prevailed in Asian countries such as China [26]. In addition, isolates of ST15/pulsotype F were more frequently seen in CA isolates than in HA isolates with borderline significance $(P=0.064)$ while isolates of ST188/ pulsotype $\mathrm{AX}$ were significantly more frequently seen in HA isolates $(p=0.049)$. The correlation of the genotype and clinical disease spectrum cannot be identified in this study, possibly due to the relatively small case number of each disease entity.

Panton-Valentine leukocidin (PVL) is a 2-component pore forming toxin (LukS-PV and LukF-PV) targeting phagocytic leukocytes $[27,28]$ and has been a marked feature of the CA-MRSA. Correlations between PVL and abscess/furuncles are high in epidemiological studies [29] despite animal models [30, 31] do not convincingly link PVL with the pathogenesis of skin lesions. It is noteworthy that PVL genes were identified in 11 MSSA isolates in this study, accounting for $8.4 \%$ of the isolates. A previous pediatric study [32] conducted in northern Taiwan showed a PVL harbor rate of $19.5 \%(14 / 71)$ in infecting MSSA isolates from 2003 to 2008. In contrast, 4.17\% was reported in China in 2008 [33] and less than $7 \%$ in the US in 2004 [34]. In this study, 9 of the 11 PVL-strain were ST59/pulsotype D, whereas the aforementioned Taiwanese pediatric study [32] showed only two ST59/pulsotype D among 19 isolates. Skin and soft tissue infection were the main focus found in PVL-strain, as shown in Table 4. The molecular characterizations of this MSSA strain was similar to those of a dominant local endemic CA-MRSA strain in Taiwan [35]. This endemic CA-MRSA clone, namely MRSA ST59, might be originated from MSSA ST59 with the acquisition of mecA gene. A phylogenetic analysis is needed and is ongoing. However, the clinical significance and implication of these PVL-positive MSSA isolates need more studies. In addition, one of the other two PVL-positive isolates was characterized as ST8/t008/pulsotype AI, similar to those of MRSA USA300, which is an endemic CA-MRSA clone prevailing in northern American and emerged in Taiwan recently [36].

Several strains with specific sequencing type deserved more elucidation. Three isolates could not be typed by PFGE and was characterized as ST398, which is a livestock-associated strain and prevailed in Europe [37], not reported from Taiwan previously. The origin of this strain could not be traced in this study. One isolate of pulsotype $\mathrm{C}$ were characterized as ST59, also similar to those of local endemic CA-MRSA clones. One isolate of pulsotype-ST30 was shared a similar characteristics of a CA-MRSA clone prevailing in Southeastern Asia [37].

Antibiotics susceptibility test revealed that the susceptibility rate exceeded $90 \%$ in most antibiotics except erythromycin, clindamycin and penicillin, which was identical to the finding in MSSA infection in Taiwanese adult population [12]. Comparing to antibiotics susceptibility in Asia and USA, the overall susceptibility rates were higher in Taiwan than in China [38], but the results were similar to pediatric patients in US [39].

There are several limitations in this study. First, this study was conducted in a single medical center and the epidemiologic features shown here may not represent the whole pediatric population in Taiwan. However, our hospital is the largest hospital in Taiwan and the case number in this study was not small, it still can partly reflect the current status of childhood MSSA infection in Taiwan. Second, though the isolates were prospectively collected, medical records of the patients were retrospectively reviewed, some risk factors for MSSA acquisition in the patients may be missed and thus the patients in HA-MSSA group might be misclassified to CA-MSSA group. Third, some of the specimen types e.g. pus, wound swabs, urine and sputum may be easily contaminated by $S$. aureus. Thus, whether or not all $S$. aureus isolates identified in this study caused active infection is somewhat questionable. However, all the isolates were clinical isolates from the patients with active diseases and were treated as such.

\section{Conclusions}

Around one-third of childhood S. aureus infections in northern Taiwan were caused by MSSA. SSTIs were the most common manifestation. The molecular characteristics of these clinical MSSA isolates were relatively diverse and with certain significant difference between CA and HA isolates. A small proportion of these MSSA isolates harbored PVL genes.

\section{Abbreviations \\ CA: Community-associated; CC: Clonal complex; CLSI: Clinical and Laboratories Standards Institute; CO: Community-onset; HA: Healthcare- associated; HO: Hospital-onset; MLST: Multilocus sequence type; MRSA: Methicillin-resistant Staphylococcus aureus; MSSA: Methicillin-sensitive Staphylococcus aureus; PFGE: Pulsed-field gel electrophoresis; PVL: Panton- Valentine leucocidin}

\section{Acknowledgements}

The authors thank the research assistants, Ya-Lin Huang and Yu-Chiao Huang for excellent technical assistance. 


\section{Funding}

This work was supported by grants from Chang Gung Memorial Hospital (CMRPG3F1851), Ministry of Science and Technology, Executive Yuan of Taiwan (MOST 106-2813-C-182A-001-B) and Medical Foundation in Memory of Dr. Deh-Lin Cheng.

\section{Availability of data and materials}

All the data are presented in the paper.

\section{Authors' contribution}

YJC \& PAC: laboratory performance, acquisition of data, analysis and interpretation of data, drafting the manuscript. CJC: conception and design, analysis and interpretation of data. YCH: conception and design, analysis and interpretation of data, modifying and revising the manuscript. All authors read and approved the final manuscript.

\section{Ethics approval and consent to participate}

This study was approved by Institutional Reviewing Board of Chang Gung Memorial Hospital (reference No: 201600590B0) and this was a retrospective study so the consent to participate was waivered by the local ethical review board.

\section{Consent for publication}

Not applicable.

\section{Competing interests}

The authors declare that they have no competing interests.

\section{Publisher's Note}

Springer Nature remains neutral with regard to jurisdictional claims in published maps and institutional affiliations.

\section{Received: 15 October 2018 Accepted: 26 April 2019} Published online: 10 May 2019

\section{References}

1. David MZ, Daum RS, Bayer AS, Chambers HF, Fowler VG, Miller LG Ostrowsky B, Baesa A, Boyle-Vavra S, Eells SJ. Staphylococcus aureus bacteremia at 5 US academic medical centers, 2008-2011: significant geographic variation in community-onset infections. Clin Infect Dis. 2014; 59(6):798-807. https://doi.org/10.1093/cid/ciu410.

2. Kaspar U, Kriegeskorte A, Schubert T, Peters G, Rudack C, Pieper DH, WosOxley M, Becker K. The culturome of the human nose habitats reveals individual bacterial fingerprint patterns. Environ Microbiol. 2016;18(7):213042.

3. David MZ, Daum RS. Community-associated methicillin-resistant Staphylococcus aureus: epidemiology and clinical consequences of an emerging epidemic. Clin Microbiol Rev. 2010;23(3):616-87.

4. Klein EY, Sun L, Smith DL, Laxminarayan R. The changing epidemiology of methicillin-resistant Staphylococcus aureus in the United States: a national observational study. Am J Epidemiol. 2013. https://doi.org/10.1093/aje/ kws273.

5. Becker K, Schaumburg F, Fegeler C, Friedrich AW, Kock R. Staphylococcus aureus from the German general population is highly diverse. Int J Med Microbiol. 2017;307(1):21-7.

6. Dantes $R, M u$ Y, Belflower R, Aragon D, Dumyati G, Harrison LH, Lessa FC, Lynfield R, Nadle J, Petit S. National burden of invasive methicillin-resistant Staphylococcus aureus infections, United States, 2011. JAMA Intern Med. 2013;173(21):1970-8

7. Laupland KB, Lyytikäinen O, Søgaard M, Kennedy K, Knudsen JD, Ostergaard C, Galbraith J, Valiquette L, Jacobsson G, Collignon P. The changing epidemiology of Staphylococcus aureus bloodstream infection: a multinational population-based surveillance study. Clin Microbiol Infect. 2013;19(5):465-71.

8. De Kraker M, Jarlier V, Monen J, Heuer O, Van De Sande N, Grundmann H. The changing epidemiology of bacteraemias in Europe: trends from the European antimicrobial resistance surveillance system. Clin Microbiol Infect. 2013;19(9):860-8.

9. Chuang YC, Chen YC, Chang SC, Sun CC, Chang YY, Chen ML, Hsu LY, Wang JT. Secular trends of healthcare-associated infections at a teaching hospital in Taiwan, 1981-2007. J Hosp Infect. 2010;76(2):143-9.
10. Wang HK, Huang CY, Huang YC. Clinical features and molecular characteristics of childhood community-associated methicillin-resistant Staphylococcus aureus infection in a medical center in northern Taiwan, 2012. BMC Infect Dis. 2017:17(1):470.

11. Chen FJ, Siu LK, Lin JC, Wang CH, Lu PL. Molecular typing and characterization of nasal carriage and community-onset infection methicillin-susceptible Staphylococcus aureus isolates in two Taiwan medical centers. BMC Infect Dis. 2012;12:343.

12. Chen P-Y, Chuang Y-C, Wang J-T, Chang S-C. Impact of prior healthcareassociated exposure on clinical and molecular characterization of methicillin-susceptible Staphylococcus aureus bacteremia: results from a retrospective cohort study. Medicine. 2015;94(5):e474. https://doi.org/10. 1097/MD.0000000000000474.

13. Morrison MA, Hageman JC, Klevens RM. Case definition for communityassociated methicillin-resistant Staphylococcus aureus. J Hosp Infect. 2006; 62(2):241.

14. DeLeo FR, Otto M, Kreiswirth BN, Chambers HF. Community-associated meticillin-resistant Staphylococcus aureus. Lancet. 2010;375(9725):1557-68.

15. Klevens RM, Morrison MA, Fridkin SK, Reingold A, Petit S, Gershman K, Ray S, Harrison LH, Lynfield R, Dumyati G, et al. Community-associated methicillinresistant Staphylococcus aureus and healthcare risk factors. Emerg Infect Dis. 2006;12(12):1991-3.

16. Chen S-Y, Wang J-T, Chen TH-H, Lai M-S, Chie W-C, Chien K-L, Hsueh P-R, Wang J-L, Chang S-C. Impact of traditional hospital strain of methicillinresistant Staphylococcus aureus (MRSA) and community strain of MRSA on mortality in patients with community-onset S. aureus bacteremia. Medicine. 2010;89(5):285-94.

17. Shah SN, Bachur RG, Simel DL, Neuman MI. Does this child have pneumonia?: the rational clinical examination systematic review. JAMA. 2017:318(5):462-71.

18. Subcommittee on Urinary Tract Infection SCoQI. Management, Roberts KB: urinary tract infection: clinical practice guideline for the diagnosis and management of the initial UTI in febrile infants and children 2 to 24 months. Pediatrics. 2011:128(3):595-610.

19. Shaikh N, Shope TR, Hoberman A, Vigliotti A, Kurs-Lasky M, Martin JM. Association between Uropathogen and pyuria. Pediatrics. 2016:138(1): e20160087. https://doi.org/10.1542/peds.2016-0087.

20. Institute CaLS. Performance Standards for Antimicrobial Susceptibility Testing: Twenty-Third Informational Supplement M100-S23. Wayne: CLSI; 2016.

21. Jolley KA, Bray JE, Maiden MCJ. Open-access bacterial population genomics: BIGSdb software, the PubMLST.org website and their applications. Wellcome Open Res. 2018;3:124.

22. Chen C-J, Huang Y-C, Su L-H, Wu T-L, Huang S-H, Chien C-C, Chen P-Y, Lu $\mathrm{M}-\mathrm{C}, \mathrm{Ko}$ W-C. Molecular epidemiology and antimicrobial resistance of methicillin-resistant Staphylococcus aureus bloodstream isolates in Taiwan, 2010. PLoS One. 2014:9(6):e101184.

23. Chen YJ, Liu KL, Chen CJ, Huang YC. Comparative molecular characteristics of community-associated and healthcare-associated methicillin-resistant Staphylococcus aureus isolates from adult patients in northern Taiwan. Medicine. 2015:94(49):e1961.

24. Chen FJ, Hiramatsu K, Huang IW, Wang CH, Lauderdale TL. Panton-valentine leukocidin (PVL)-positive methicillin-susceptible and resistant Staphylococcus aureus in Taiwan: identification of oxacillin-susceptible mecA-positive methicillin-resistant S. aureus. Diagn Microbiol Infect Dis. 2009;65(4):351-7.

25. Ho CM, Lin CY, Ho MW, Lin HC, Peng CT, Lu JJ. Concomitant genotyping revealed diverse spreading between methicillin-resistant Staphylococcus aureus and methicillin-susceptible Staphylococcus aureus in Central Taiwan. J Microbiol Immunol Infect. 2016;49(3):363-70.

26. Yu F, Li T, Huang X, Xie J, Xu Y, Tu J, Qin Z, Parsons C, Wang J, Hu L, et al. Virulence gene profiling and molecular characterization of hospital-acquired Staphylococcus aureus isolates associated with bloodstream infection. Diagn Microbiol Infect Dis. 2012;74(4):363-8.

27. Loffler B, Hussain M, Grundmeier M, Bruck M, Holzinger D, Varga G, Roth J, Kahl BC, Proctor RA, Peters G. Staphylococcus aureus Panton-Valentine leukocidin is a very potent cytotoxic factor for human neutrophils. PLoS Pathog. 2010;6(1):e1000715.

28. Saeed K, Gould I, Esposito S, Ahmad-Saeed N, Ahmed SS, Alp E, Bal AM, Bassetti M, Bonnet E, Chan M, et al. Panton-Valentine leukocidin-positive Staphylococcus aureus: a position statement from the international society of chemotherapy. Int J Antimicrob Agents. 2018;51(1):16-25. 
29. Shallcross LJ, Fragaszy E, Johnson AM, Hayward AC. The role of the PantonValentine leucocidin toxin in staphylococcal disease: a systematic review and meta-analysis. Lancet Infect Dis. 2013;13(1):43-54.

30. Li M, Cheung GY, Hu J, Wang D, Joo HS, Deleo FR, Otto M. Comparative analysis of virulence and toxin expression of global community-associated methicillin-resistant Staphylococcus aureus strains. J Infect Dis. 2010;202(12): 1866-76.

31. Chi CY, Lin CC, Liao IC, Yao YC, Shen FC, Liu CC, Lin CF. Panton-valentine leukocidin facilitates the escape of Staphylococcus aureus from human keratinocyte endosomes and induces apoptosis. J Infect Dis. 2014;209(2): 224-35.

32. Chiu YK, Lo WT, Wang CC. Risk factors and molecular analysis of PantonValentine leukocidin-positive methicillin-susceptible Staphylococcus aureus colonization and infection in children. J Microbiol Immunol Infect. 2012; 45(3):208-13.

33. Wu D, Wang Q, Yang Y, Geng W, Wang Q, Yu S, Yao K, Yuan L, Shen X. Epidemiology and molecular characteristics of community-associated methicillin-resistant and methicillin-susceptible Staphylococcus aureus from skin/soft tissue infections in a children's hospital in Beijing, China. Diagn Microbiol Infect Dis. 2010;67(1):1-8.

34. Diep BA, Sensabaugh GF, Somboona NS, Carleton HA, Perdreau-Remington F. Widespread skin and soft-tissue infections due to two methicillin-resistant Staphylococcus aureus strains harboring the genes for Panton-Valentine leucocidin. J Clin Microbiol. 2004;42(5):2080-4.

35. Chuang YY, Huang YC. Molecular epidemiology of community-associated meticillin-resistant Staphylococcus aureus in Asia. Lancet Infect Dis. 2013: 13(8):698-708

36. Huang YC, Chen CJ, Kuo CC, Lu MC. Emergence, transmission and phylogeny of meticillin-resistant Staphylococcus aureus sequence type 8 (USA300) in Taiwan. J Hosp Infect. 2018;100(3):355-8. https://doi.org/10. 1016/j.jhin.2018.02.014

37. Chen CJ, Huang YC. New epidemiology of Staphylococcus aureus infection in Asia. Clin Microbiol Infect. 2014;20(7):605-23.

38. Changchien C-H, Chen S-W, Chen Y-Y, Chu C. Antibiotic susceptibility and genomic variations in Staphylococcus aureus associated with skin and soft tissue infection (SSTI) disease groups. BMC Infect Dis. 2016;16:276.

39. Sutter DE, Milburn E, Chukwuma U, Dzialowy N, Maranich AM, Hospenthal DR. Changing susceptibility of Staphylococcus aureus in a US pediatric population. Pediatrics. 2016;137(4):e20153099. https://doi.org/10.1542/peds. 2015-3099.

Ready to submit your research? Choose BMC and benefit from:

- fast, convenient online submission

- thorough peer review by experienced researchers in your field

- rapid publication on acceptance

- support for research data, including large and complex data types

- gold Open Access which fosters wider collaboration and increased citations

- maximum visibility for your research: over $100 \mathrm{M}$ website views per year

At BMC, research is always in progress.

Learn more biomedcentral.com/submissions 